\title{
The convection heat transfer rate evaluation of a 6-cylinder in-line tur- bocharged direct-injection diesel engine
}

\author{
Brahim Menacer*, Abdelkader Soualmia**, Cherif Belhout***, Mostefa Bouchetara**** \\ Department of Mechanical Engineering, University of Sciences and the Technology of Oran, BP 1505 El -MNAOUER, \\ USTO 31000 ORAN, Algeria, E-mail:*acer.msn@hotmail.fr, **soualmia.aek@hotmail.fr, ***belhout.magi@gmail.com, \\ ****mbouchetara@hotmail.com \\ cross $^{\text {ref }}$ http://dx.doi.org/10.5755/j01.mech.23.4.14898
}

\section{Introduction}

Heat losses are a major limiting factor for the performances of internal combustion engines such as incylinder pressure, temperature, power, efficiency, exhaust emissions and component thermal stresses [1], [2]. Furthermore, convective heat transfer phenomena cause thermally induced mechanical stresses compromising the reliability of engine components. The ability to predict a convective heat transfer in engines plays an important role in engine development. Today, predictions are increasingly being done with numerical simulations at an earlier stage of engine development. These methods must be based on the understanding of the principles of convective heat transfer. Lawton [3] measured the instantaneous heat flux at the surface of a cylinder head in a motored diesel engine at different speeds. It found that the observed heat flux was different from the predicted one according to existing quasi-steady theories. However, when the gas temperature external to the boundary layer and the wall temperature were equal, in particular it was found that there was a significant heat flux. The maximum heat flux was found to occur at about $8^{\circ}$ bTDC. Furthermore, it also concluded that the heat flux during compression was larger than that during expansion. Mohammadi et al. [4] used a CFD code to compute the average heat flux and heat transfer coefficient on the cylinder head, liner, piston and intake and exhaust valves of a spark ignition engine. In this study the Woschni correlation was used to compare with the computationally determined total heat transfer on the combustion chamber. From this comparison, close agreement was observed. Results showed that maximum heat flux in each part occurred at maximum cylinder pressure. It also showed that the higher heat flux was on the intake valves, and the heat flux on the cylinder head was more than on the piston. Uchimi and coworkers [5] studied the conditions of heat loss to combustion chamber walls in a direct injection diesel engine. To characterise the heat loss to the entire piston surface of this engine, measurements of instantaneous heat flux were conducted at different points (piston crown, side and bottom of the cavity). Results showed that there were differences in the piston surface instantaneous temperature wave form, the instantaneous heat flux wave form amplitude and the peak phase between different measuring points. The results also showed that the heat loss to the piston surface relative to the calorific value of fuel was higher than those of the gasoline engine measured in earlier studies. In this paper, we propose a thermodynamic single-zone computational model based on the step-by-step filling and emptying method proposed by
Watson et al [6] and valid for turbocharged diesel engine. This study focuses on the investigation and analysis of the effect of sevral engine parameters (thermodynamic and geometric) on the convective heat flux and max heat flux from fluide to the cylinder wall of the combustion chamber to provide a better understanding on the convective heat transfer of a turbocharged compression ignition engine. For this purpose, a computer simulation programme is developed in Fortran language, and use of a commercial GT-Power software for comparison and validation of the results.

\section{Engine modeling and correlation}

In internal combustion engines, heat loss from combustion gases to the cylinder wall strongly influences the thermodynamics of the engine cycle. This heat loss is an important part of the energy balance, which influences gas temperature and pressure, piston work, engine performance, and emissions. Ordinarily, the convective heat transfer from the cylinder gases to the walls is calculated by estimating the engine-wall temperature and basing the heat flux on the difference between the gas and wall temperatures. The heat transfer coefficient used for the calculation is usually adopted from empirical Hohenberg's correlation. In this article, all assomptions and approximations are cited in following paragraphe (Fig. 1):

- No spatial variations were considered, so the model was said to be zero-dimensional.

- The combustion chamber contents are fully mixed and spatially homogeneous in terms of composition and properties during the whole engine cycle.

- The working fluid is air, which continuously circulates in a closed loop (cycle) and always behaves as an ideal gas.

- The heat release is calculated based on the first law of thermodynamics by taking the average value of pressure versus crank angle.

- The in-cylinder pressure and temperature are uniform across the combustion chamber.

- The heat is only transferred to the combustion chamber walls and the heat losses through other engine parts are neglected.

- The heat flow through the combustion chamber is a steady one-dimensional process.

- The coefficient of convective heat transfer is uniform across the combustion chamber.

- In the intake manifold, the thermal transfers are negligible in the gas-wall interface ; this hypothesis is 
acceptable since the manifold temperature is near to the one of gases that it contains.

- The variation of the mass in the intake manifold depends on the compressor mass flow and the flow through of valves when they are open.

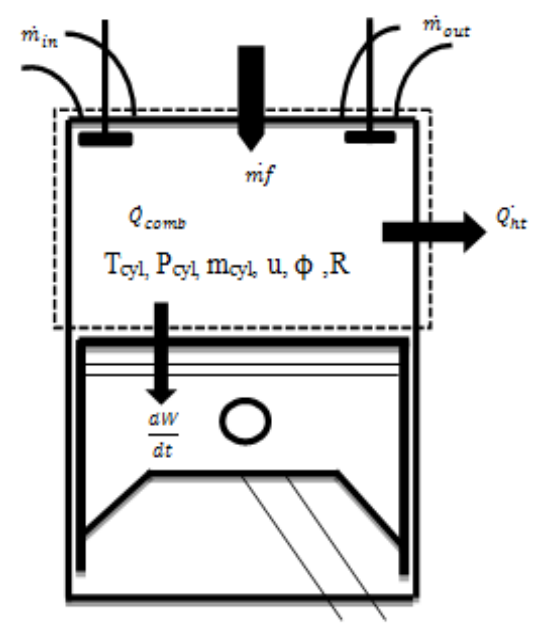

Fig. 1 Engine cylinder as an open thermodynamic system

Eq. (1) was used to model the single zone base on the $1^{\text {st }}$ law of thermodynamic:

$d U=d Q-d W+h d m$.

The chemical energy released during the calculation is calculated using Eq. (2): where $\frac{d Q}{d t}$ is the heat released due chemical energy, $\frac{d Q_{h t}}{d t}$ is the convection heat transfer, $\frac{d m_{i n}}{d t}$ is the mass flow through the intake valve, $\frac{d m_{\text {out }}}{d t}$ is the mass flow through the exhaust valve, $Q_{L H V}$ is the lower heating value of fuel, $C_{p}$ is the specific heat at constant pressure, $C_{v}$ is the specific heat at constant volume, $T_{c y l}$ is the wall temperature. This ordinary differential equation can easily be solved numerically for the net heat release trace:

$$
\begin{aligned}
& \frac{d Q}{d t}=\frac{d Q_{\text {in }}}{d t}+\frac{d Q_{\text {comb }}}{d t}-\frac{d Q_{\text {out }}}{d t}-\frac{d Q_{h t}}{d t}= \\
& =C_{p} \frac{d m_{i n}}{d t} T_{a}+\frac{d m_{f b}}{d t} Q_{L H V}-C_{p} \frac{d m_{\text {out }}}{d t} T_{c y l}-\frac{d Q_{h t}}{d t} .
\end{aligned}
$$

\subsection{Heat loss model in 0-dimensional model}

Heat transfer from the combustion chamber to the cylinder wall occurs by convection and radiation. In diesel engines, radiation heat transfer is negligible because its effect is very small, due to low soot and low temperature combustion [7], [8]: therefore it is ignored [9]. By applying the assumption of steady heat transfer for the present study, the convective heat transfer can be calculated by multiplying the simultaneous heat transfer coefficient, the instantaneous heat exchange area and the temperature difference [10]:

$$
\frac{d Q_{h t}}{d t}=A_{w} h_{t}\left(T-T_{w}\right),
$$

where $T_{w}$ is the temperature walls of the combustion chamber (bounded by the cylinder head, piston head and the cylinder liner). From the results of Rakapoulos and al. [11], $T_{w}$ is assumed constant.

The instantaneous wall area $A_{w}$ in $\mathrm{m}^{2}$ is the sum of the piston, cylinder head and cylinder wall area, which is:

$$
\begin{aligned}
& A_{w}=\frac{\pi D^{2}}{4}+\left(\frac{\pi D^{2}}{4}+\frac{4 V_{c}}{D}\right)+ \\
& +\left[\pi D \frac{L}{2}\left(R+1-\cos \omega t-\sqrt{R^{2}-\sin ^{2}(\omega t)}\right)\right],
\end{aligned}
$$

where $V_{c}$ is the minimum cylinder volume (or the Clearance volume, $\left.\mathrm{m}^{3}\right) ; R=\frac{2 l}{L}$ is the ratio of connecting rod length to crank radius; $l$ is the connecting rod length, $\mathrm{m}$; $L$ is the piston stroke, $\mathrm{m} ; D$ is the cylinder bore, $\mathrm{m}$.

\subsection{Correlation of Hohenberg}

In 0-dimensional modelling, an empirical submodel is used for the heat transfer coefficient, where the model does not contain any physical or chemical principles. In this paper, the heat transfer coefficient is modelled using the Hohenberg's correlation. On the other hand, this correlation includes some modifications to the Woschni equation, where it uses instantaneous cylinder volume instead of bore. In addition to that, the characteristic velocity is replaced with the effective gas velocity, and the temperature exponent has also changed [7]. The Hohenberg correlation is [12]:

$$
h_{t}(t)=\frac{k_{h o h} p_{c y l}^{0.8}\left(\bar{v}_{p i s}+c\right)^{0.8}}{V_{c y l}^{0.6} T_{c y l}^{0.4}},
$$

where $p_{c y l}$ is the cylinder pressure; $V_{c y l}$ is the in cylinder gas volume at each crank angle position and $k_{h o h}$ is the constant of Hohenberg, which characterize the engine, $\left(k_{h o h}=130\right)$ and $c$ is the calibration constant that Hohenberg suggested to be 1.4 for the engine he studied [7].

The mean piston speed $\bar{S}_{p}, \mathrm{~m} / \mathrm{s}$, defined as:

$$
\bar{S}_{p}=2 L N / 60
$$

where $N$ is the engine rotational speed, rpm.

\subsection{Calculation of the in-cylinder volume}

The instantaneous cylinder volume at any crank angle location can be determined from the compression ratio, the stroke, bore and connecting rod length [13]:

$$
V_{c y l}(t)=V_{c}\left[1+\frac{c_{r}-1}{2}\left(R+1-\cos (\omega t)-\sqrt{R^{2}-\sin ^{2}(\omega t)}\right)\right],(7)
$$


where $t$ is the time corresponding to crank angle measured with respect to the top dead center, $s ; \omega$ is the engine speed, $\mathrm{rad} / \mathrm{s} ; c_{r}$ is the compression ratio $\left(c_{r}=1+V_{d} / V_{c}\right) ; V_{d}$ is the displacement volume, $\mathrm{m}^{3}$.

From these parameters, the instantaneous piston speed can be obtained :

$$
S_{p}=\frac{\pi}{2} \bar{S}_{p} \sin (\omega t)\left(1+\frac{\cos (\omega t)}{\sqrt{R^{2}-\sin ^{2}(\omega t)}}\right) .
$$

The instantaneous piston speed $S_{p}$ is zero at the beginning of the stroke and approaches its maximum at the middle of the stroke. It goes to zero again at the end of the stroke.

\subsection{Calculation of the in-cylinder pressure}

The in-cylinder pressure change in the zerodimensional single-zone model is calculated by the approach suggested by [14]:

$$
\begin{aligned}
& \frac{d p_{c y l}}{d t}=\frac{\gamma}{V_{c y l}}\left[R T_{i n} \frac{d m_{i n}}{d t}-R T_{c y l} \frac{d m_{c y l}}{d t}-p_{c y l} \frac{d V_{c y l}}{d t}\right] \times \\
& \times \frac{\gamma-1}{V_{c y l}}\left[\frac{d m_{f b}}{d t} Q_{L H V}-\frac{d Q_{h t}}{d t}\right],
\end{aligned}
$$

where $\lambda$ is the specific heat ratio $\left(\lambda=C_{p} / C_{v}\right)$.

\subsection{Calculation of the in-cylinder temperature}

Once the pressure is obtained from equation (9), the in-cylinder temperature is determined theoretically by using the ideal gas law [15]:

$$
p_{c y l} V_{c y l}=m_{c y l} R T_{c y l},
$$

where $R$ is gas constant, $\mathrm{kJ} / \mathrm{kg} \mathrm{K}$.

$$
\begin{aligned}
& \frac{d T_{c y l}}{d t}=\left[\left(\frac{d Q_{h t}}{d t}+\sum\left(h_{0} \frac{d m}{d t}\right)_{i n}-\sum\left(h_{0} \frac{d m}{d t}\right)_{o u t}+\right.\right. \\
& \left.+\frac{d Q_{c o m b}}{d t}-u \frac{d m_{c y l}}{d t}\right) \frac{1}{m_{c y l}}-\frac{R T_{c y l}}{V_{c y l}} \frac{d V_{c y l}}{d t}- \\
& \left.-\frac{\partial u}{\partial \phi} \frac{d \phi}{d t}\right] /\left(\frac{\partial u}{\partial T_{c y l}}\right) .
\end{aligned}
$$

In equation (11), many terms will be zero in some control volumes all or some of the time. For examples: $\frac{d V_{c y l}}{d t}$ is zero for the manifolds, $\left(h_{0} \frac{d m}{d t}\right)_{i n}$ and $\left(h_{0} \frac{d m}{d t}\right)_{\text {out }}$ are zero for the cylinder, $\frac{d m_{f b}}{d t}$ is zero the manifolds, $u \frac{d m_{c y l}}{d t}$ is zero for the cylinder except for mass addition of fuel during combustion, $\frac{d Q_{h t}}{d t}$ is neglected for the inlet manifolds, $\frac{\partial u}{\partial \phi}$ is zero for the cylinder except during combustion (when fuel is added, hence $\phi$ changes), specific enthalpies $\left(h_{0}\right)_{\text {in }}$ and $\left(h_{0}\right)_{\text {out }}$ (except the specific enthalpy of formation $h_{f o r}$ ) are constant values. To evaluate the differential Eqs. (9) or (11), all terms of the right side must be found. The most adapted numerical solution method for these equations is the Runge-Kutta method.

\section{Simulation programs of supercharged diesel engines with FORTRAN and GT-Power}

\subsection{The thermodynamic simulation program in FORTRAN language}

A quasi-one dimensional thermodynamic model was developed in this paper to study the effect of varying engine parameters on the convective heat flux as a function of the crank angle throughout the important processes (compression, combustion and expansion) in the combustion chamber of a 6-cylinder turbocharged diesel engine. The thermodynamic simulation program was written on the FORTRAN code. Its solves the governing differential equations that represent the rates of change of the cylinder temperature, pressure and convective heat flux. The FORTRAN heat release code was written with a modular structure, where the bulk of the main program consists of subroutine call commands. In Fig. 2, each box represents a subroutine that is called by the main program. Most of the computation in the heat release code takes place in these subroutines. This architecture allows the code to be understood and modified easily by future contributors. To initialize a convective heat transfer calculation, the operational parameters must be defined through the 'Input/Output Parameters' window. Here, the location of the source data (The valve and injection timings, engine geometry, engine speed and inlet pressure were entered into the model) is identified, as well as the destination of the heat release output. The subroutines that are first called by the main program are used either to prepare the input data for calculation, or to determine important parameters that are used in the heat release calculation. Once these parameters have been calculated, the cylinder convective heat transfer, work, and internal energy are determined and then summed to arrive at the heat release. Additional subroutines compute the mass fraction burned and rate of heat release. The heat release program uses implicit iteration techniques to converge on final heat release values. The program recalculates the mass fraction burned at each crank angle and compares its value at EVO with its value from the previous iteration. If the difference between the two is greater than some user-defined small value, the program will continue the iteration process. Otherwise, the program ceases to iterate and the final output is reported. For the closed cycle period, Watson recommended the following engine calculation crank angle steps: $10^{\circ} \mathrm{CA}$ before ignition, $1{ }^{\circ} \mathrm{CA}$ at fuel injection timing, $2^{\circ} \mathrm{CA}$ between ignition and combustion end, and finally $10^{\circ} \mathrm{CA}$ for expansion (6). 


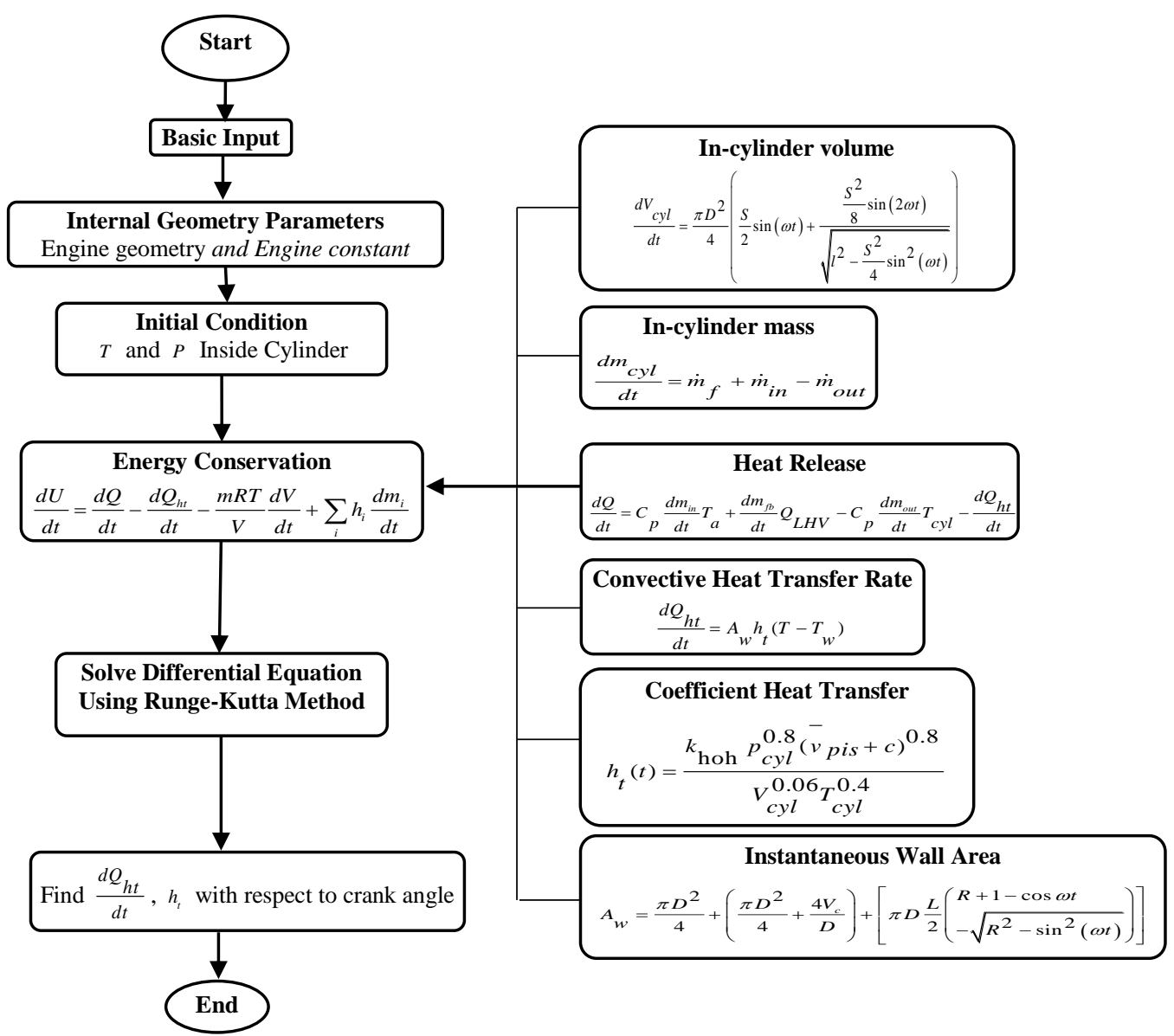

Fig. 2 Organization chart of a 6-cylinder turbocharged diesel engine modeling process

\subsection{Simulation with the GT-Power software}

The software uses one dimensional gas dynamics to represent the flow and heat transfer in the components of the engine model. The user constructs the model by dragging and dropping objects in the graphical user interface GT-SUITE, where the component database offers a broad range of engine components. After linking the components with connection objects the user may define properties for each component, setting up simulation options such as convergence criteria and specify desired output plots before running the simulation. To model the engine in GT-Power there are objects like cylinders, crankcases, pipes, turbochargers and so on, that are easy to modify by desire. Fig. 3 shows the GT-Power model of a 6-cylinders turbocharged diesel engine and intercooler. In the modeling view, the engine, turbocharger, intercooler, fuel injection system, intake and exhaust system are considered as components interconnected in series. The line of exhaust manifold of the engine is composed in three volumes; the cylinders are grouped by three and emerge on two independent manifold, component two thermodynamic systems opened of identical volumes, and a third volume smaller assures the junction with the wheel of the turbine. The turbocharger consists of three main parts that the efficien$\mathrm{cy}$, the turbine, the compressor and the bearings. The tur- bine and compressor are mounted on the same shaft and rotate with the same angle velocity. The turbine is driven by the energy available in the exhaust gases and the compressor increases the inlet air density prior to each cylinder. The maximum power output an engine can deliver is limited by the amount of fuel that can be burned efficiently in the cylinder. The mass of fuel that can be burned is depended of the amount of fresh air that is inducted during each cycle. By using a turbocharger more mass of air can be inducted into each cylinder. The fuel economy of a turbocharger engine is influenced by the same factors as the naturally aspirated engine. The compression ratio is of great importance, a turbocharged engine makes a reduction of the geometric compression ratio compared to a naturally aspirated compression ignition engine necessary. There is relation between the boost pressure and the geometric and effective compression ratio. A high boost pressure requires a low geometric compression ratio, which leads to an increase in the fuel consumption [16]. In the engine the intercooler is used to cool the air that comes from the compressor, because when using a turbocharger the air density increase and so the inlet temperature will increase, also. The intercooler is an air-water cross flow heat exchanger. The cooler consists of a big volume with many small pipes where the internal air is flowing through [17]. 


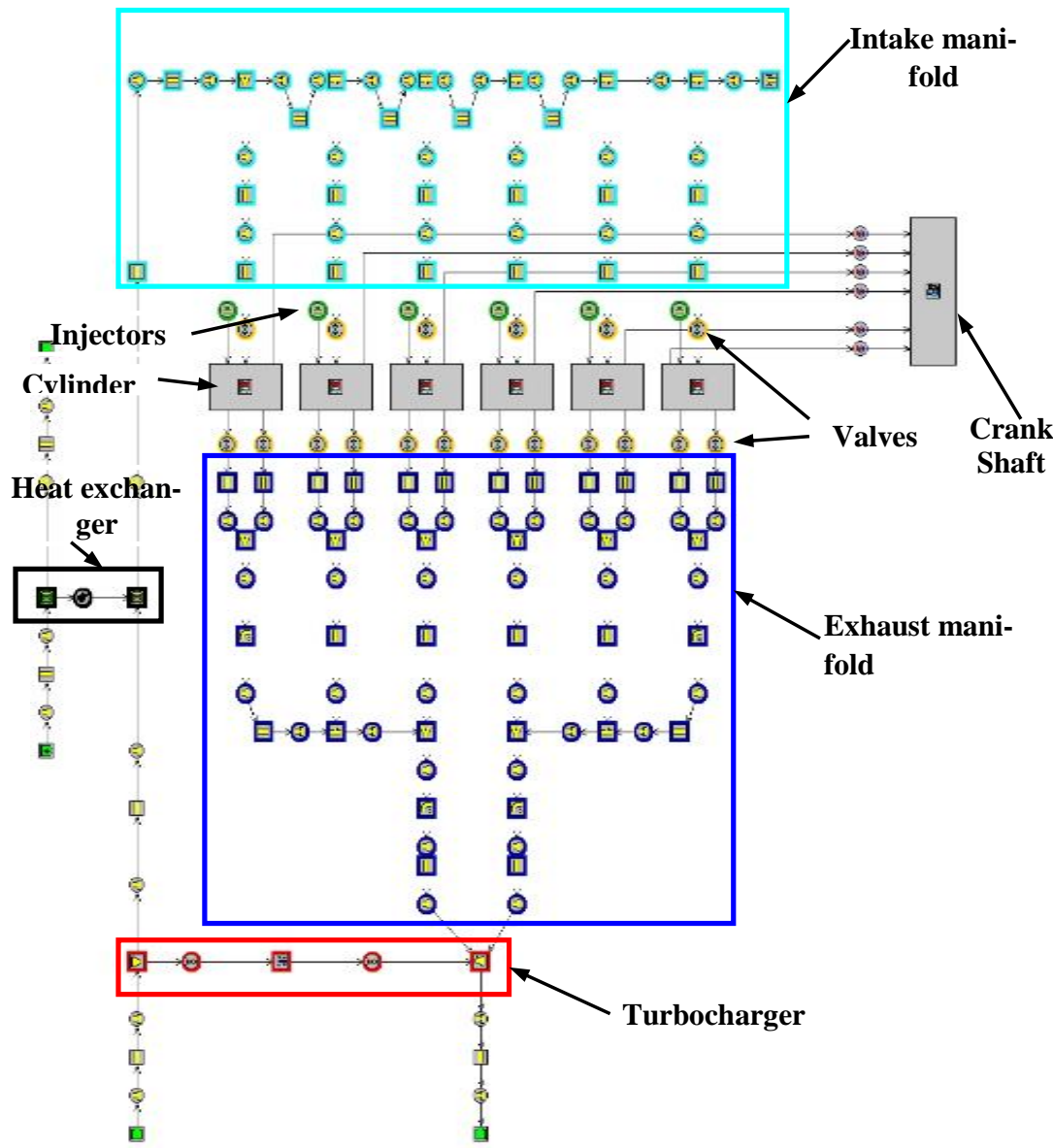

Fig. 3 A 6-cylinders turbocharged diesel engine model using the GT-Power software [18]

\section{Results and discussion}

The chosen engine parameters to evaluate the convective heat transfer versus crank angle in this study are: the engine speed $N$, the compression ratio $C_{r}$, the stroke bore ratio $R_{s b}=L / D$, the injection timing $T_{i n j}$, the cylinder wall temperature $T_{\text {wall }}$ and the injected fuel mass $m_{f}$.

The main parameters of the chosen turbocharged direct-injection diesel engine are showed in the following table (Table 1) [18], [16].

Table 1

Engine specifications [16]

\begin{tabular}{|l|c|}
\hline \multicolumn{1}{|c|}{ Engine parameters } & Values \\
\hline Bore $D, \mathrm{~mm}$ & 120.0 \\
\hline Stroke $S, \mathrm{~mm}$ & 175.0 \\
\hline Displacement volume $V_{d}, \mathrm{~cm}^{3}$ & 1978.2 \\
\hline Connecting rod length $l, \mathrm{~mm}$ & 300.0 \\
\hline Compression ratio, - & 16.0 \\
\hline Inlet valve diameter, $\mathrm{mm}$ & 60 \\
\hline Exhaust valve diameter, $\mathrm{mm}$ & 38 \\
\hline Inlet Valve Open IVO, ${ }^{\circ} \mathrm{CA}$ & 314 \\
\hline Inlet Valve Close $\mathrm{IVC},{ }^{\circ} \mathrm{CA}$ & -118 \\
\hline Exhaust Valve Open EVO, ${ }^{\circ} \mathrm{CA}$ & 100 \\
\hline Exhaust Valve Close EVC, ${ }^{\circ} \mathrm{CA}$ & 400 \\
\hline Injection timing, ${ }^{\circ} \mathrm{CA}$ & $15^{\circ} \mathrm{BTDC}$ \\
\hline Fuel system, - & $\begin{array}{c}\text { Direct } \\
\text { injection }\end{array}$ \\
\hline Firing order, - & $1-5-3-6-2-4$ \\
\hline
\end{tabular}

\subsection{Effect of the engine speed}

As the engine speed increases, the gas velocity into and out of the engine will increase and this leads to a rise in convection heat transfer coefficients. This effect increases the heat transfer occurring during intake and exhaust strokes and even during the early part of the compression stage, whereas, during the combustion and power stroke. Figs. 4 and 5 shows the influence of the engine speed $(N=1200,1400$ and $1600 \mathrm{rpm})$ on the convective heat flux and the max convective heat flux versus crank angle at full load, advance injection of $15^{\circ}$ bTDC. From this figures, when an engine runs at higher speeds, the time per cycle is less. The combustion in the engine occurs over

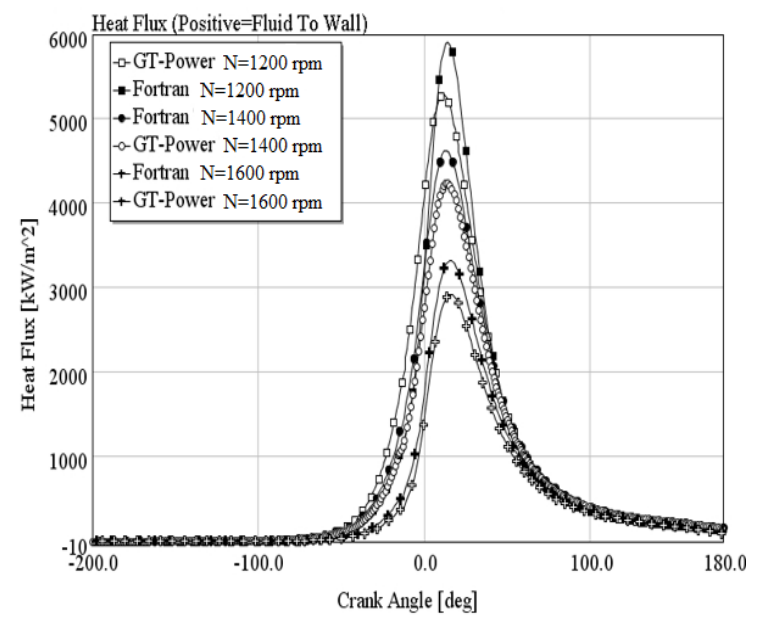

Fig. 4 Convective heat flux versus crank angle for engine speed of 1200, 1400 and $1600 \mathrm{rpm}$ 


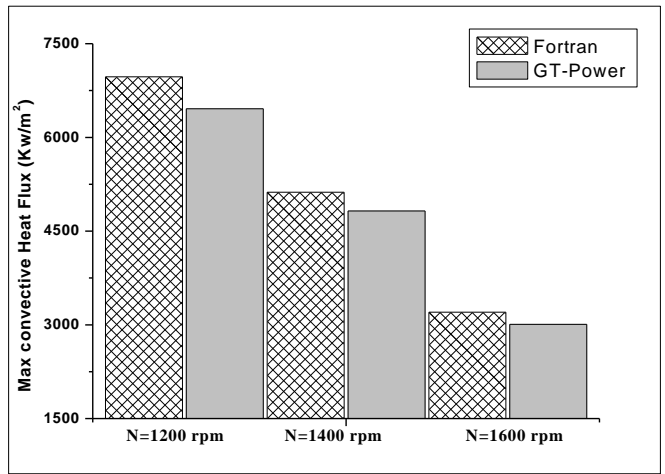

Fig. 5 Max convective heat flux for engine speed of 1200 , 1400 and $1600 \mathrm{rpm}$

about the same burn angle at all speeds, which means the time of combustion is less at higher speeds, resulting in less time for self-ignition and knock. However, the time for heat transfer per cycle will be less and that means the engine runs hotter, which leads to increased knock problems. If the engine speed augments of $200 \mathrm{rpm}$ (from 1400 to $1600 \mathrm{rpm})$ then, the max value of convective heat flux decreased an average of $15 \%$. Therefore, it can be observed that some engines have an increased knock problem at higher speeds where as some have less problems at smaller engine speeds [19].

\subsection{Effect of the compression ratio}

Figs. 6 and 7 shows the influence of the compression ratio $(\mathrm{Cr}=16: 1,19: 1$ and 21:1) on the convective heat flux and the max convective heat flux versus crank angle at full load, advance injection of $15^{\circ} \mathrm{bTDC}$ and engine speed of $1400 \mathrm{rpm}$. From this figures, increasing the compression ratio raises the heat flux slightly. For example, raising the compression ratio to $2: 1$ (from 19:1 to 21:1) increases the maximum values of convective heat flux by about 4 percent for GT-Power and the elaborate software. Several of the combustion characteristics change as the compression ratio increases such as cylinder gas pressure, peak gas temperature, gas motion and convective heat transfer, and also the combustion becomes faster as the compression ratio increases [20]. In general, the higher the compression ratio, the more expansion cooling will occur during the power stroke, which leads an increasing the convective heat transfer and to cooler exhaust.

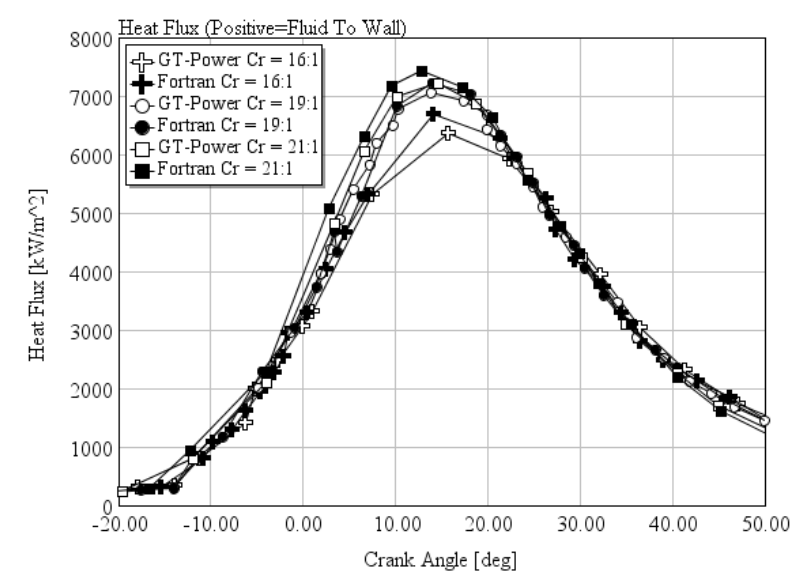

Fig. 6 Convective heat flux versus crank angle for compression ratio of $16: 1,19: 1$ and 21:1

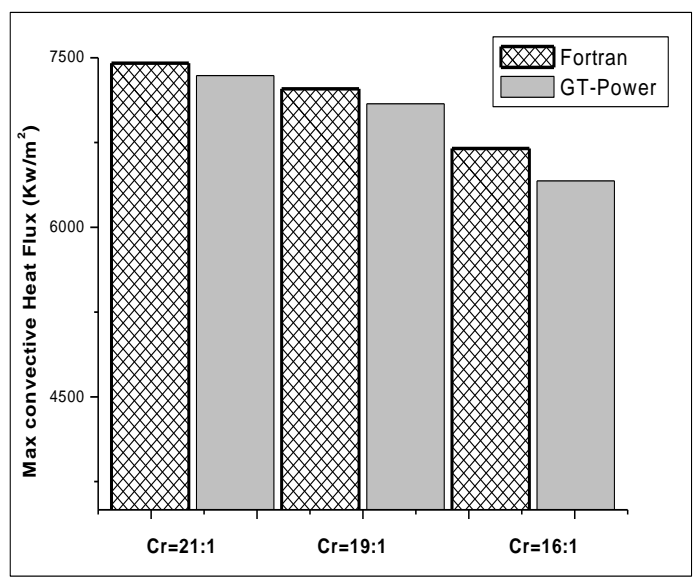

Fig. 7 Max convective heat flux for compression ratio of $16: 1,19: 1$ and $21: 1$

\subsection{Effect of the stroke-bore ratio}

The influence of the stroke bore ratio on the convective heat flux of a turbocharged diesel engine is represented in Figs. 8 and 9. If this parameter increases, the friction losses are important with increasing the engine speed, as result; the convective heat flux increases [21]. If the stroke bore ratio augments of 0.5 (from 1.5 to 2 ) then, the max value of convective heat flux increased an average of $6 \%$.

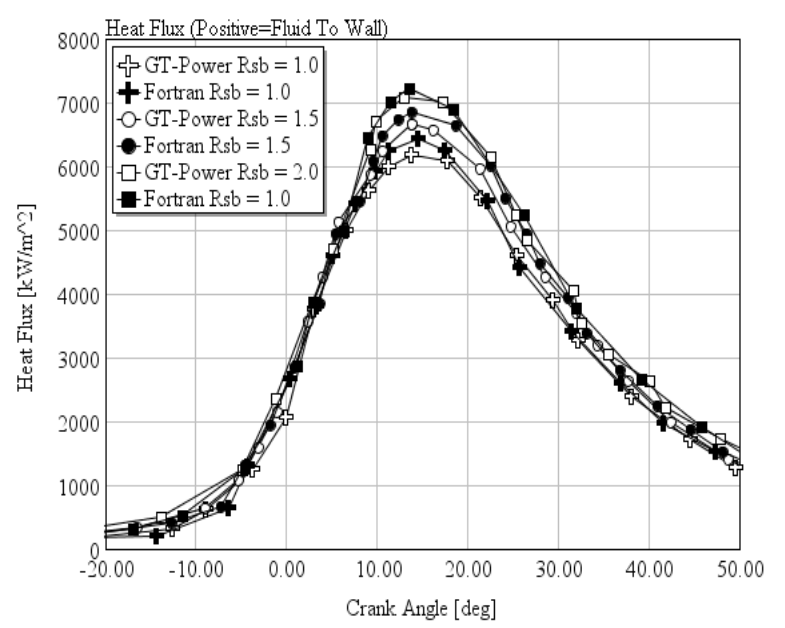

Fig. 8 Convective heat flux versus crank angle for the stroke bore ratio of 1.0, 1.5 and 2.0

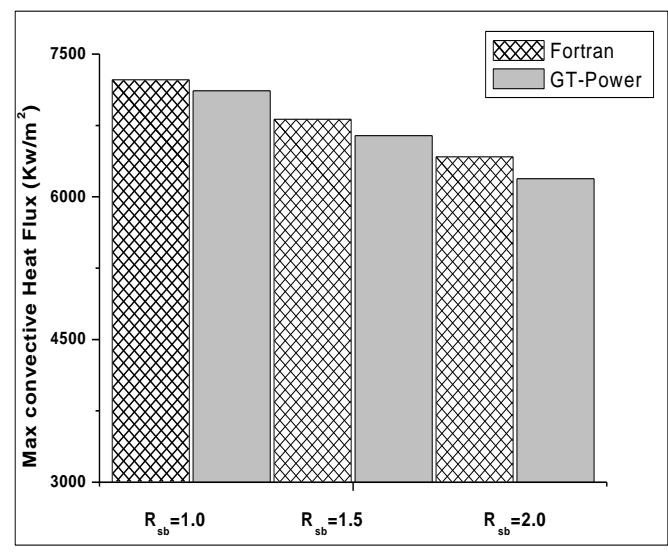

Fig. 9 Max convective heat flux for the stroke bore ratio of $1.0,1.5$ and 2.0 


\subsection{Effect of the cylinder wall temperature}

Different materials are used in manufacturing the cylinder and the piston components of engines, which results in different operating temperatures. The commonly used materials are cast iron and aluminium, which have substantially different thermal conductivities. The influence of the cylinder wall temperature is represented also in Figs. 10 and 11, more the difference temperature between gas and wall cylinder is high, then the losses by convective exchange is higher [18]. If the cylinder wall temperature increase by $100^{\circ} \mathrm{K}$ (from $450^{\circ} \mathrm{K}$ to $550^{\circ} \mathrm{K}$ ), the max convective heat flux decrease about $12 \%$. So there is substantial interest in using materials that could operate at much higher temperatures so that the heat loses from the working fluid would be reduced.

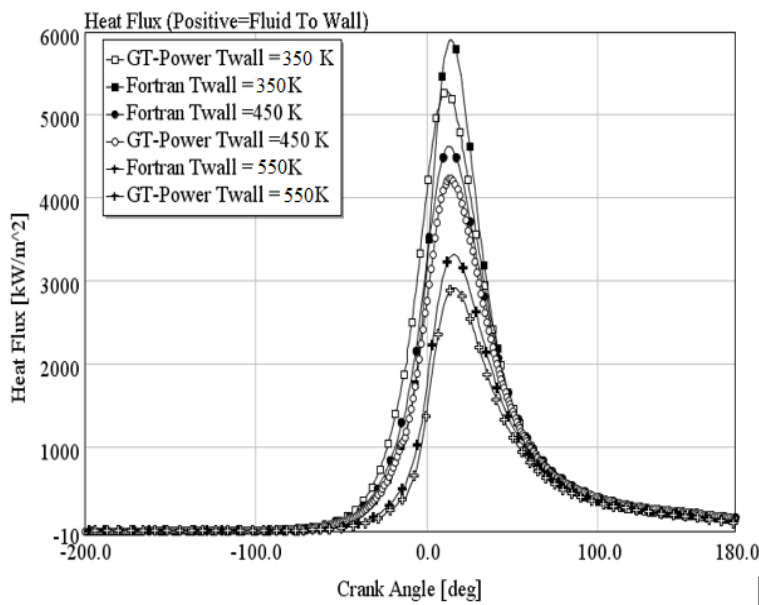

Fig. 10 Convective heat flux versus crank angle for the cylinder wall temperature of 350,450 and $550 \mathrm{~K}$

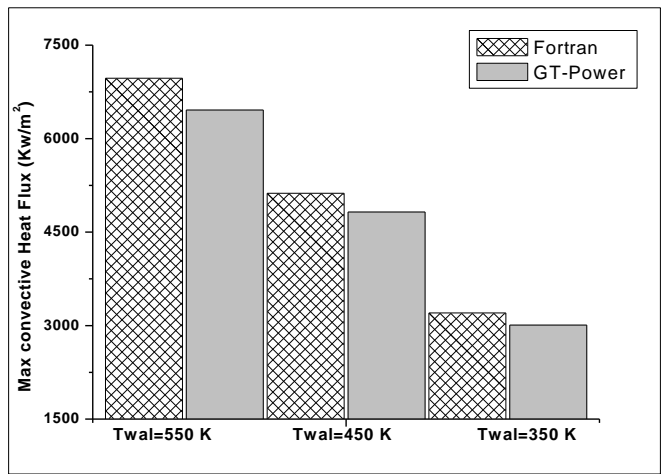

Fig. 11 Max convective heat flux for the cylinder wall temperature of 350,450 and $550 \mathrm{~K}$

\subsection{Effect of the injection timing}

An important factor affecting the compression ignition engine performances is the injection timing. As the injection timing is advanced (from 5 aTDC to 15 bTDC) in the diesel engine, the convective heat flux is increased, as shown in Figs. 12 and 13. The same trend would be expected in spark injection engines when the spark timing is advanced [19]. If the advance injection is advanced (from 5 aTDC to 15 bTDC) then the max convective heat flux from fluid to the combustion chamber wall increases to $15 \%$ respectively. Retarding the injection timing makes the combustion occur later and decreases the burned gas temperature. Late ignition timing extends the combustion process further into the expansion stroke, which results in smaller convective heat transfer.

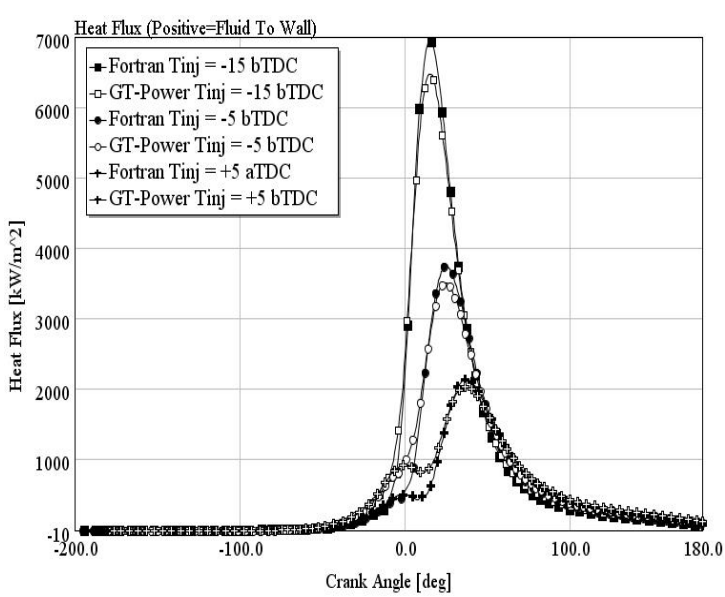

Fig. 12 Convective heat flux versus crank angle for injection timing of $15^{\circ}, 5^{\circ} \mathrm{bTDC}$ and $5^{\circ}$ aTDC

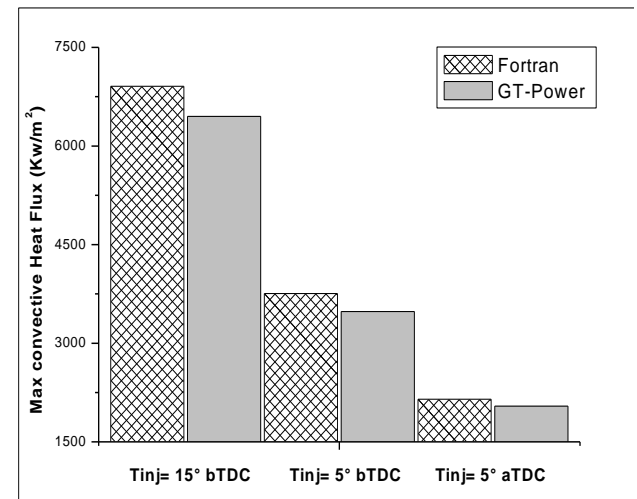

Fig. 13 Max convective heat flux for injection timing of $15^{\circ}, 5^{\circ} \mathrm{bTDC}$ and $5^{\circ}$ aTDC

\subsection{Effect of the injected masse fuel}

As the conventional diesel engines are qualitygoverned engines, to vary the load or speed, the quantity of fuel to be injection will be varied, there by varying the quality of mixture. Figs. 14 and 15 shows the variation of the convective heat flux and the max convective heat flux versus crank angle for different masse fuel injected at advance injection of $15^{\circ} \mathrm{bTDC}$, compression ratio of $16: 1$,

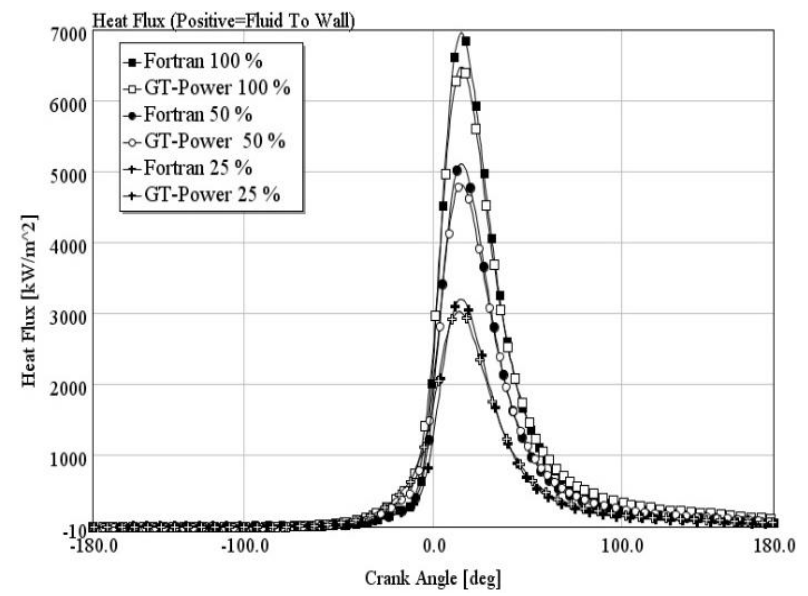

Fig. 14 Convective heat flux versus crank angle for injected mass fuel of $25 \%, 50 \%$ and $75 \%$ load 


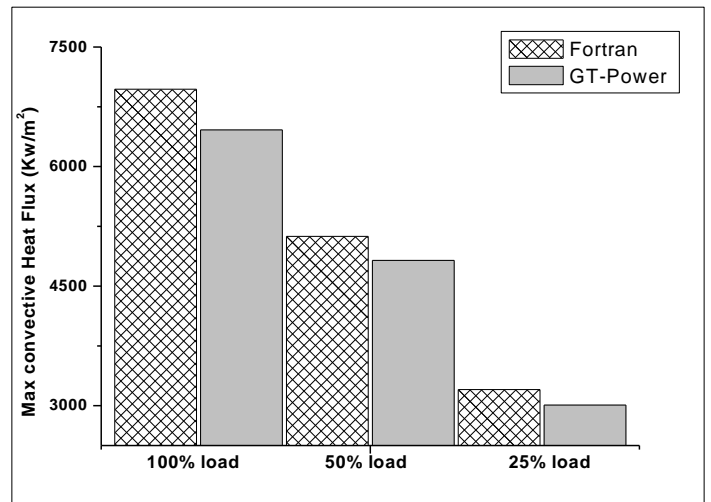

Fig. 15 Max convective heat flux for injected mass fuel of $25 \%, 50 \%$ and $75 \%$ load

and $N=1400 \mathrm{rpm}$. If the mass fuel injected in the cylinder increases, then more fuel is burned in the cylinder and therefore more heat is released that leads to higher convective heat flux, gas temperatures and pressures. If the masse fuel injected in the cylinder increase by $50 \%$ (from $50 \%$ to $100 \%$ ), so the max value of convective heat flux increase of $15 \%$.

\section{Conclusions}

A theoretical simulation model was developed for the analysis of the convective heat transfer phenomena, which occur in the combustion chamber of a 6-cylinder turbocharged direct injection diesel engine. Effort has been put into building a physical model based on the filling and emptying method that can predict the convective heat flux versus crank angle from fluid to the combustion chamber wall for different engine parameters. The following parameters: stroke-bore ratio and compression ratio have a small influence on convective heat flux and max value of convective heat flux. While engine speed, angle of the start injection, mass fuel injected and cylinder wall temperature have great influence on convective heat flux and max value of convective heat flux. Finally, the presented model can significantly contribute to play a very significant role to investigate the quality of combustion and the convective heat flux inside the combustion chamber for different engine parameters.

\section{References}

1. Huang, J. et al. 2009. Experimental investigation on the performance and emissions of a diesel engine fuelled with ethanol-diesel blends, Applied Thermal Engineering 29: 2484-2490.

http://dx.doi.org/10.1016/j.applthermaleng.2008.12.016

2. Irimescu, A. 2013. Convective heat transfer equation for turbulent flow in tubes applied to internal combustion engines operated under motored conditions, Applied Thermal Engineering 50: 536-545.

http://dx.doi.org/10.1016/j.applthermaleng.2012.06.051

3. Lawton, B. 1987. Effect of compression and expansion on instantaneous heat transfer in reciprocating internal combustion engines, Proceedings of the institution of mechanical engineers, Part A: Journal of Power and Energy 201(3): 175-186.

http://dx.doi.org/10.1243/PIME_PROC_1987_201_022 -02.
4. Mohammadi, A.; Yaghoubi, M. 2010. Estimation of instantaneous local heat transfer coefficient in sparkignition engine, International Journal of Thermal Sciences 49: 1309-1317. http://dx.doi.org/10.1016/j.ijthermalsci.2009.12.010.

5. Uchimi, T.; Taya, K.; Hagihara, Y.; Kimura, S.; Enomoto, Y. 2000. Heat loss to combustion chamber wall in a D.I diesel engine," first report: Tendency of heat loss to piston surface, JSAE 21: 133-135. http://dx.doi.org/10.1016/S0389-4304(99)00071-5.

6. Watson, N.; Pilley, A.D.; Marzouk, M. 1980. A combustion correlation for diesel engine simulation, In: SAE Technical Paper, 1980-800029. http://dx.doi.org/10.4271/800029.

7. Heywood, J.B. 1988. Internal combustion engine fundamentals, McGraw-Hill, New York. http://dx.doi.org/10.1016/S0082-0784(75)80383-3.

8. Ladommatos, N.; Xiao, Z.; Zhao, H. 2005. The effect of piston bowl temperature on diesel exhaust emissions, Proceedings of the Institution of Mechanical Engineering, part D: J. Automobile Engineering 219: 371388. http://dx.doi.org/10.1243/095440705X6550.

9. Robinson, K.; Hawley, J.G.; Hammond, G.P.; Owen, N.J. 2003. Convective coolant heat transfer in internal combustion engines, Proceedings of the Institution of Mechanical Engineers, Part D: Journal of. Automobile Engineering 217: 133-146. http://dx.doi.org/10.1243/09544070JAUTO450.

10. Menacer, B.; Bouchetara, M. 2013. Simulation and prediction of the performance of a direct turbocharged diesel engine. Simulation: Transactions of the Society for Modeling and Simulation International 89: 13551368. http://dx.doi.org/10.1177/0037549713499249.

11. Rakopoulos, C.D.; Taklis, G.N.; Tzanos, E.I. 1995. Analysis of combustion chamber insulation effects on the performance and exhaust emissions of a DI diesel engine using a multi-zone model, Heat Recovery Systems and CHP 15: 691-706. http://dx.doi.org/10.1016/0890-4332(95)90048-9.

12. Hohenberg, G.F. 1979. Advanced approaches for heat transfer calculations, SAE Technical Paper, 1979790825. http://dx.doi.org/10.1016/j.applthermaleng.2003.11.002

13. Lounici, M.S.; Loubar, K.; Balistrou, M.; Tazerout, M. 2010. Investigation on heat transfer evaluation for a more efficient two-zone combustion model in the case of natural gas SI engines, Applied Thermal Engineering 31: 319-328.

http://dx.doi.org/10.1016/j.applthermaleng.2010.09.012

14. Rashedul, H.K.; Kalam, M.A.; Masjuki, H.H.; Ashraful, A.M.; Imtenan, S.; Sajjad, H.; Wee, L.K. 2014. Numerical study on convective heat transfer of a spark ignition engine fueled with bioethanol, International Communications in Heat and Mass Transfer 58: 33-39.

http://dx.doi.org/10.1016/j.icheatmasstransfer.2014.08. 019.

15. Ibrahim, A.; Bari, S. 2009. A comparison between EGR and lean-burn strategies employed in a natural gas SI engine using a two-zone combustion model, Energy Conversion and Management 50: 3129-3139. http://dx.doi.org/10.1016/j.enconman.2009.08.012. 
16. Gamma, Technologies. 2009. GT-Power User's Manual, GT-Suite Version 7.0; GT-Power product flyer, the Industry Standard. Available from Internet: http://www.gtisoft.com/img/broch/broch_gtpower.pdf.

17.Soyhan, H.S.; Yasar, H.; Walmsley, H.; Head, B.; Kalghatgi, G.T.; Sorusbay, C. 2009. Evaluation of heat transfer correlations for HCCI engine modeling, Applied Thermal Engineering 29: 541-549.

http://dx.doi.org/10.1016/j.applthermaleng.2008.03.014

18. Menacer, B.; Bouchetara, M. 2015. Computational thermodynamic of a turbocharged direct injection diesel engine. Mechanika 21(1): 40-50. http://dx.doi.org/10.5755/j01.mech.21.1.8690.

19. Sanli, A.; Ozsezen, A.N.; Kilicaslan, I.; Canakci, M. 2008. The influence of engine speed and load on the heat transfer between gases and in-cylinder walls at fired and motored conditions of an DI diesel engine, Applied Thermal Engineering 28: 1395-1404. http://dx.doi.org/10.1016/j.applthermaleng.2008.10.021

20. Robinson, K.; Wilson, M.; Leathard, M.J.; Hawley, J.G. 2007. Computational modelling of convective heat transfer in a simulated engine cooling gallery, Proceedings of the Institution of Mechanical Engineers, Part D: Journal of. Automobile Engineering 221: 1147-1157. http://dx.doi.org/10.1243/09544070JAUTO450.

21. Torregrosa, A.; Olmeda, P.; Degraeuwe, B.; Reyes, M. 2006. A concise wall temperature model for DI diesel engines, Applied Thermal Engineering 26: 13201327.

http://dx.doi.org/10.1016/j.applthermaleng.2005.10.021
Brahim Menacer, Abdelkader Soualmia, Cherif Belhout, Mostefa Bouchetara

\section{THE CONVECTION HEAT TRANSFER RATE EVA- LUATION OF A 6-CYLINDER IN-LINE TUR- BOCHARGED DIRECT-INJECTION DIESEL ENGINE}

S u m m a r y

The in-cylinder convective heat transfer from the combustion gas to the cylinder wall of the combustion chamber has a strong effect on the diesel engine performances. This study contribute to the knowing in this area for the event of the convective heat transfer from fluid to the cylinder wall of a turbocharged diesel engine with sixcylinder direct injection operating under steady-state conditions. An optimized choice of correlation was applied for the evaluation of heat transfer coefficient, which is the Hohenberg's correlation. We developed a computer program for simulating the operation of a six-cylinder direct injection turbocharged diesel engine, and using a commercial GT-Power software to validate the simulation results. The influence of certain engine parameters (thermodynamic and geometric) on the convective heat flux and its maximum value are studied in the present paper. The results show that the convective heat transfer characteristics as a function of crank angle of the six cylinder turbocharged diesel engine strongly depend on the engine injection timing, the cylinder wall temperature and load for the both softwares; FORTRAN and GT-Power.

Keywords: 0-Dimensional model, Thermodynamic and Geometric parameters, Convective heat transfer, Hohenberg's correlation, Computational simulation, Diesel engine, GT-Power software.

Received May 03, 2016 